\title{
Voices from the Classroom: Experiences of Teachers of Deaf Students with Additional Disabilities
}

\author{
Millicent Malinda Musyoka ${ }^{1}$, Mary Anne Gentry ${ }^{1}$, James Joseph Bartlett ${ }^{1}$ \\ ${ }^{1}$ Lamar University, USA \\ Correspondence: Millicent Malinda Musyoka, Lamar University, USA
}

Received: October 8, 2015 Accepted: October 21, 2015 Online Published: November 5, 2015

doi:10.11114/jets.v4i2.1113 URL: http://dx.doi.org/10.11114/jets.v4i2.1113

\begin{abstract}
The purpose of this research is to investigate experiences of K-12 classroom teachers of deaf students with additional disabilities. Today, more deaf and hard of hearing students are identified as having additional disabilities (Bruce, DiNatale \& Ford, 2008; Ewing, 2011; Gallaudet Research Institute, 2011; Jones, Jones \& Ewing, 2006; Mitchell \& Karchmer, 2004); there is a need to explore ways of providing educational services to these students. Utilizing a phenomenological design, data were collected using survey questionnaires, focus groups and individual interviews. Several themes emerged, such as the typical school day, previous training, and continuous professional development. Understanding the experiences of the K- 12 teachers can provide valuable information for deaf education teacher preparation programs.
\end{abstract}

Keywords: deaf students, deaf education, teacher preparation, teacher's experiences

\section{Introduction}

Generally, deaf education teacher preparation programs have focused on preparing teachers who work with students who are deaf. The issue of additional disabilities along with deafness is seldom considered. Current statistics of deaf students with additional disabilities has increased (Whelan \& Kretschmer, 1996; Van Naarden, Decoufle, \& Caldwell, 1999; Schildroth and Hotto, 1996). The most recent data showed that, approximately 55.2\% of deaf students have an additional disability (GRI, 2005, 2006, 2008). Further, Guardino (2008) argues, "the percentage of students with additional disabilities is likely to be higher, since about $5.6 \%$ of administrators or teachers from various programs did not respond to the GRI survey" (p.56).

Despite the increase, Borders and Bock's (2012) survey reported only $26 \%$ of the teacher preparation programs in deaf education in the U.S. offered courses that focused on teaching deaf students with additional disabilities. Of these programs, $16 \%$ offered a course in behavior management, additional disabilities, and academic or behavioral interventions. This lack of preparedness has been observed to impact more graduating teachers joining the profession (Moores, 2001; Miller, Brownwell \& Smith, 1999) and teachers' challenge to attend to various students' needs in the classroom (George, George, Gersten, \& Grosenick, 1995; Heyns, 1988; Miller, Brownwell, \& Smith, 1999; Singer, 1993). Consequently, it is critical that deaf education teacher preparation programs understand teachers' experiences while working with deaf students with additional disabilities.

The most prevalent additional disabilities among deaf students are learning disabilities, autism, intellectual disabilities, cerebral palsy, attention deficit disorders and emotional-behavioral disorders (Ewing \& Jones, 2003; Gallaudet Research Institute (GRI), 2011; Luckner \& Carter, 2001). In a sample of 37, 828 deaf children enrolled in special education programs, GRI (2011) reported the following: 8.3\% mental retardation (Cognitive disabilities), $8.0 \%$ learning disability, 5.5\% ADD/ADHD, $5.5 \%$ low vision, deafblindness, Ushers Syndrome, 5.3\% developmental delay, 4.4\% orthopedic impairment, $1.3 \%$ emotional disturbance, $1.7 \%$ autism, $0.3 \%$ traumatic brain injury, $14.3 \%$ other health conditions reported, $14.0 \%$ not reported, for a total of $38.9 \%$ deaf with additional disabilities.

Additional disabilities occur in tandem with deafness because the etiologies or causes of deafness often to these additional disabilities, as does, prenatal infections such as maternal rubella, complications of Rh factor, and meningitis (Bruce, DiNatale \& Ford, 2008; Luckner and Carter, 2001; Silberman, Bruce \& Nelson 2004). Due to the presence of more than one disability, teaching these students is not a simple task. These additional disabilities require teachers to attend to additional educational needs besides the deafness. In particular, challenges are noted in making decisions 
related to educational placement, curriculum planning, implementation and assessment (Guardino, 2008; Jones, 1984; J.C. v. California School for Deaf California, 2006; Perigoe \& Perigoe, 2004).

The purpose of a phenomenological approach is to identify and study a phenomenon or experience from the perspective of how it is perceived by the participants in a specific situation. The goal of this study is to represent information from the perspective of the research participant(s). The current study was guided by the following research questions:

1. What are the experiences of teachers of the deaf, teaching deaf students with additional disabilities?

2. What are the main challenges faced by these teachers?

3. Do teachers of deaf students with additional disabilities trained in Deaf education perceive such training as effective?

4. How do teachers of deaf students with disabilities describe their school support?

\section{Method}

\subsection{The Design of the Study}

The researchers of this qualitative study employed a phenomenological research design to identify and study a phenomenon or experience from the perspective of how it is perceived by the participants in a situation. According to Bogdan and Taylor (1975), the phenomenologist focuses on what people say and do as a product of how they interpret their world. In order to capture the process of interpretation, they emphasized, "empathic understanding or an ability to reproduce in one's mind the feelings, motives and thoughts behind the action of others" (Bogdan and Taylor, 1975, p. 14). Phenomenological research method was chosen because the actions and experiences are intentional, primarily a consciousness of or an experience of something (Sokolowski, 2000). Also, it is the most appropriate research method because the goal of the study is not to generalize the findings to the whole deaf education teacher population, but to understand the essence of the experience investigated.

\subsection{The Phenomenological Process}

This study adopted the five phenomenological process described by Moustakas (1994). These processes include Epoche, Phenomenological Reduction, Imaginative Reduction Synthesis of Meaning and Essences. The first step is the Epoche. The researchers acknowledged their bias and knowledge of the issues in the field. They were engaged in the Epoche process before and during the interview. The next step in the phenomenological process is the phenomenological reduction. Phenomenological reduction involves two steps namely, Bracketing and Horizonalizing. With bracketing the researchers center everything they are doing on the topic and the research question. In this study, researchers had to bracket expectations and assumptions of the participants' experiences. To do so, the researchers developed an interview protocol and interview questions to assist in blocking personal opinion or any distractions to the interview. The concept of Horizonalizing involved treating every statement and observation as equally importance. During data analysis these statements and observations were used to identify those important to the phenomenon studied. This process was followed by clustering the horizons into themes and then into a logical textual description of the phenomenon. After phenomenological reduction the next step was imaginative variation. This process allowed the researchers to view the phenomenon in study from different sides with a goal to describe the "what" and the "how" of the experience in question and uncover the essence of the phenomenon. In this study the Imaginative Variation included identifying the main themes or context that account for the development of the phenomenon.

The final step in phenomenological study is synthesis of meaning and essences. This was developed from in-depth imaginative and reflective study of the phenomenon. According to Moustakas the essences of any experience can never be fully explained but they represent individual researchers' standpoint.

\subsection{Participants}

The sampling procedures used in this study included purposeful sampling strategy. Purposeful sampling was used to select information-rich cases for study from which the researchers can learn a great deal about issues central to the research (Patton, 2000). According to Patton (2000) there are various strategies for purposefully selecting information rich cases. For this study the criterion sampling strategy was used. Criterion sampling ensured that participants included in the study had to meet predetermined standards. The criterion used in selecting the participating teachers was their experience teaching a deaf student that had been assessed and identified to have additional disabilities. According to Creswell (1998), the sample size for a phenomenological study ranges from 1-10 and can be from the same or different location. Following the above stated sampling procedures; four teachers participated in the survey questionnaire, individual interview and classroom observation sessions.

Participating teachers were contacted through the school principals and superintendents. Prior to participating in the research, the researchers requested permission from each research participant and provided consent forms to document 
the participant's agreement to participate in the research project and to have the interview recorded.

\subsection{Data Collection}

Data was collected from three teachers in two schools for the deaf and one teacher in a deaf education program within a regular school in the United States. The data collection process involved classroom observations, individual interviews and teacher survey questionnaires.

\subsubsection{Instrumentation}

This research utilized a survey questionnaire that elicited respondents' experiences teaching deaf students with additional disabilities. Both survey questionnaire items and interview questions were derived from discussion with students taking a course on teaching deaf students with multiple disabilities, student interns experience and college instructors and internship/practicum supervisors. A pretest of the survey questionnaire items and the interview protocols was conducted with a group of students who were currently taking or had completed a course on multiple disabilities and deafness.

\subsubsection{Interview Process}

The interviews were not recorded, but instead, field notes were taken in writing. Interviews were conducted one-on-one with the researchers and each participant. All interviews were conducted in the teachers' classrooms. The interview questions were broad questions to help the researcher obtain rich descriptions of the experience (Creswell, 2008; Mertens, 2010; Moustakas, 1994). The researchers, using semi-structured questions, were able to probe the participants to elicit detailed experiences.

\subsection{Data Analysis}

The analysis adhered to the phenomenological methods prescribed by Moustakas (1994) which is a modification of Van Kaam $(1959,1966)$. The analysis is outlined in Figure 1.

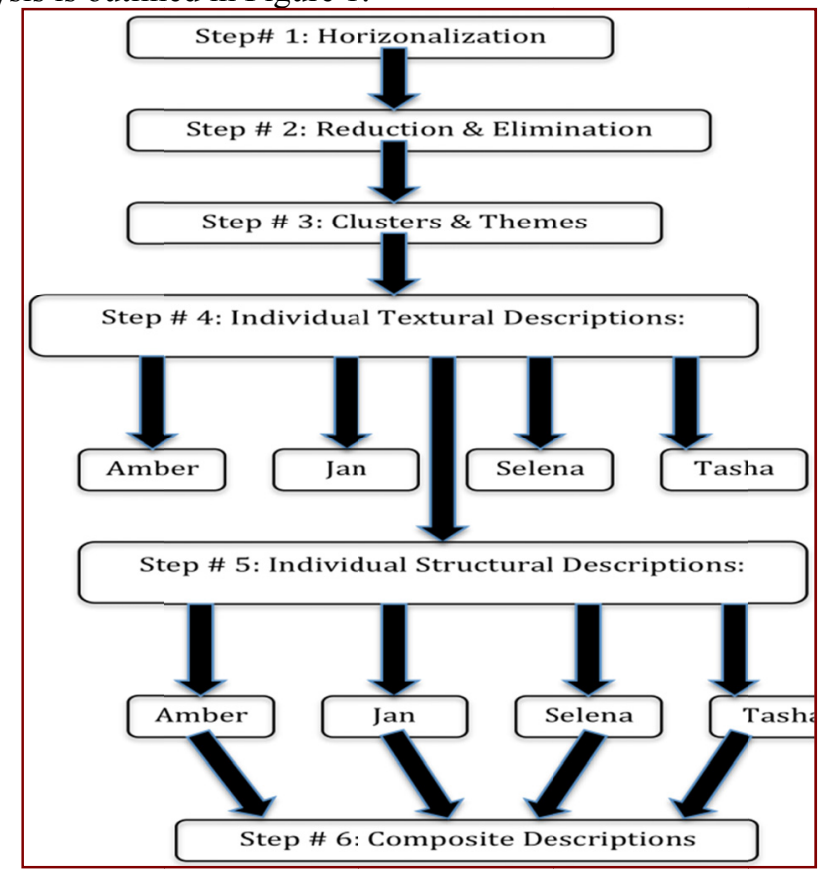

Figure 1. Moustakas phenomenological data analysis process

The first step in data analysis was horizonalization in which the research identified and grouped all data relevant to the phenomenon studied. After transcribing the interview data, the researchers read every statement, phrase or word to identify relevant experience the second step was reduction and elimination. During the second step all repetitive and redundant information was removed. Next step is clustering and thematizing the invariant constituents of the experience. The participants' responses were grouped into meaningful units that appeared to be crucial characteristics of the teachers' experiences and provided an understanding of the teachers' experiences with deaf students with additional disabilities. The meaning units that included the teachers' statements or expressions of their experiences were identified and clustered into themes. Themes developed were used to develop for each participant an individual textural description that represented the rich description of the lived experience of each teacher of deaf students with additional disabilities. This was followed by an individual structural description that was developed from individual textural description and imaginative variation. All of the individual textual descriptions and individual structural description 
were integrated into a textural-Structural description for each research participant in order to present the meanings and essences of the experience by incorporating the invariant constituent themes. Finally, from the individual Textural-structural descriptions a composite description was developed that represented the meanings and essences of the experience of the group as a whole. The composite textural description allowed for a blending of the individual descriptions to provide a richer description of the lived experience of becoming a teacher through the collective perspectives of the individual participants and the researcher. The composite textural description provided for an explanation of the conditions that collectively existed and a possible explanation of how the experience developed.

\section{Findings}

The findings of the phenomenological data analysis are presented in two parts. The first part includes the individual textural and individual structural descriptions while the second is the composite description. The individual textural and individual structural descriptions were presented as four case studies that included thematic descriptions of the participants' experiences. Each case presentation begins with a general discussion of the participant's background and professional context. There were 1) the journey in becoming a teacher of deaf students with additional disabilities; 2) what happened during a typical day; 3) what happened during curriculum planning and implementation; 4) prior training; 5) mentorship, teamwork and administrative support; and 6) communication and; 7) collaboration with parents. The individual descriptions were followed by a composite description that provided the meanings and essences for all the four teachers.

\subsection{Individual Textural and Structural Descriptions}

\subsubsection{Ms. Amber}

Ms. Amber is a female, middle school teacher who has over 10 years teaching deaf students with additional disabilities in a school for the deaf. She has a bachelor's degree in general education and a masters degree in deaf education. She is also certified in Deaf education.

Through classroom observations and interview sessions with Ms.. Amber the researchers identified all the seven themes as follows:

\section{Theme 1: Journey in becoming teacher of deaf students with additional disabilities}

Ms. Amber shared her initial experiences when she was assigned a class with deaf students with special needs after teaching deaf students for ten years.

I did not know anything about deaf students with special needs.... it was a new experience to me... now I am much better. I began by being assigned to teach two deaf students with additional disabilities, and then with time I became a teacher for deaf with additional disabilities. Today my class has four students...

She recalled an experience with behavior problems that required patience with the students. It was challenging because parents and administration did not understand how she was handling the problem. This misunderstanding created even more pressure.

I had to be patient with them...they all learn differently...always open to learn what they are trying to communicate...I also have to stay focused because sometimes no one seemed to understand them. I think students know their expectations. I understand they each have different special needs and learning and I try to make accommodations in how I attend to their needs. My goal is to provide a safe, comfortable learning environment, where students with different learning needs can learn together.

When being asked about the best experience in this journey as a teacher and how she has been able to go through challenges, she responded,

I want my students to be the best at who they are. I have come a long way with my class-administration actually notes on the changes we have made particularly on behavior management... My students behave much better to one another and they have learned to wait and take turns in receiving my attention. I explained to them over and over, we all have to be patient.

I made it through by engaging in various exercises such as jogging, yoga and meditation. I still do. Also, it's important for new teachers to research and read material on the various disabilities and seek for curriculums and ready set website with students' interests.

Finally, Ms. Amber believed that she was in the process of evolving as a teacher. She appeared to brace herself for a more challenging experience every day.

\section{Theme 2: Influence of teacher preparation}

Ms. Amber did not reflect on the teacher preparation program. It appeared that the program did not adequately prepare her for the challenges of teaching these students. She stated that the teacher preparation program did provide a 
theoretical understanding from IEP trainings

When I graduated from college, I taught deaf students. I knew about deaf students but not deaf students with special needs. When I started teaching special needs students I was not prepared and had little to refer to from my training years. Also she recalled her lack of crucial skills training in classroom management. She attributed her ability to teach and manage her class to years of experience.

\section{Theme 3: Reflection on a typical day as a teacher for deaf students with additional disabilities}

Ms. Amber's day begins with a common meeting in which they talk about the calendar, numbers, and days of the week, weather, any birthdays or field trips. Student individual expectations and activities were also included. Twice a week, the students have cooking and art class. Ms. Amber's typical day was a depiction of her overall teaching role and experience. She reported assumptions as to what she felt administration, fellow faculty, and parents would expect of her as a teacher for deaf students with additional disabilities. Ms. Amber expressed that her current duties created role conflict with her training and the expected role as a teacher.

\section{Theme 4: Curriculum planning and implementation}

Ms. Amber expressed the challenges in her early years teaching deaf students with additional disabilities related to the lack of curriculum and training. Planning was consuming and challenging. Following the Unique Learning System curriculum, her class curriculum is organized by monthly schedules and is aligned to State Educational and Transition Standards.

A well-defined class organization and structure was noted. Classroom management focused on positive reinforcement. She noted the importance of taking time to understand students, and that exploratory learning provided opportunities to learn more about her students.

\section{Theme 5: Mentorship, teamwork and School support.}

The absence of a well-defined mentor was noted. Ms. Amber reported independent decisions on curriculum planning, teaching strategies, classroom behavior and assessment. Her initial years with students with additional disabilities were challenging and felt she would have benefited by having a mentor.

I didn't have an assigned mentor but I had another teacher that was already working with deaf students with additional disabilities that I consulted with when I had a question. Most of the time I figured it all by myself as a first time teacher with special needs students, I wished I had a mentor to take me through the expectation and challenges...I didn't have the experience with special needs... having someone who had taught these students as a mentor would have assisted me in planning and carrying out behavior management... the administration and parents expected me to deal with the student, but I didn't have someone to guide me through...

Also, felt most faculty perceived teachers of deaf students with additional disabilities as different and identified them with their students. She also noted the need for specific professional development.

\section{Theme 6: Collaboration with Parents}

Ms. Amber noted need for collaboration with parents. She expressed that deaf students with additional disabilities required constant family support to ensure success with IEP goals. She felt the administration needed to emphasize family support. Without parental support, she experienced conflict in maintaining students' basic needs, including clothing and feeding. She mentioned cases where she even spent her own money.

\section{Theme 7: Communication}

Ms. Amber expressed that even though the mode of communication was ASL/ English, this was not the case with the deaf students with additional disabilities. The mode of communication in her classroom included the use of American Sign Language (ASL), Spoken English and Total Communication (TC). The choice of communication depended on the communication and educational needs of each student. She concluded that most of her students' communicated in ASL or TC.

\subsubsection{Ms. Jan}

Ms. Jan has 15 years teaching deaf students. while 5 of those years have been with deaf students with additional disabilities. Ms. Jan has a bachelor's degree in general education and a master's degree in deaf education. She has deaf education and special education certification. She teaches high school students with special needs in a school for the deaf. Her experiences in teaching deaf students with additional disabilities were captured in the seven themes as follows:

\section{Theme 1: Journey in becoming a teacher of deaf students with additional disabilities}

As a former resource teacher, Ms. Jan is now teaching high school deaf students with special needs. Her experience is 
attributed to the quality of the support she received from faculty and administration. She attributed her success in accomplishing her role as a teacher to the quality of the support she received from other faculty and school administration.

It was challenging the first time as a teacher for deaf students with additional disabilities. I interacted with most deaf students who needed technical support before I started teaching. There were some challenges... of course as new teachers you have to strive... I had supportive faculty and administration.

She noted that her roles included job counselor, family member, and friend. This caused added concern about students' current needs and future independence. She felt life skills and career skills were necessary for their future.

\section{Theme 2: Influence of teacher preparation}

Ms. Jan noted that her teacher preparation program did not include deaf students with special needs. She had no practicum experience with deaf students with special needs. She reported the same situation with other teachers of students with special needs.

We all learned on the job what to do, and, with time and practice, we developed our skills on how to teach these students. We keep on learning what to do.

Ms. Jan mentioned the need for in-service on teaching deaf students with special needs because teacher preparation programs might not attend to all the needs in the field of deaf education. She noted that in the past 10 years or so, while she had been teaching in the school for the deaf, they have never had any workshops that focused on deaf students special needs.

\section{Theme 3: Reflection on a typical day as a teacher for deaf students with additional disabilities}

As a high school teacher of special needs deaf students, the focus was vocational and transition. The students had various special needs, including autism, learning disabilities, physical disabilities (cerebral palsy, muscular dystrophy) and other health related issues.

The students' IEP goals include vocational goals and high school transitional goals

Her day began with discussing the calendar activities such as, date, weather, who is present in class and what is happening in the world. Ms. Jan uses "News-2-you" which is a component of the Unique Learning System curriculum. Various students are engaged in the reading and comprehension in a variety of ways, including using ASL, print English, pictures or Symbolstix. Symbolstix is part of the curriculum in which lively stick figures are used to portray people, activities and events in the story.

The students' IEP goals include vocational goals and high school transitional goals. Hence, the students have an opportunity to develop working skills through job assignments in the school. The teacher networks with local agencies to secure students with intern jobs or jobs upon completion of high school.

\section{Theme 4: Curriculum planning and implementation}

When I started teaching, we had to decide what to teach and how to do it. We didn't have a curriculum. Sometimes, I used the regular curriculum to get ideas on what to teach. The school has supported us by getting us a curriculum we are currently using.

In the past, Ms. Jan developed lessons and materials. This changed when the school purchased the Unique Learning System curriculum for special needs. She also uses Accelerated Reader (AR), a reading management program supports computerized assessment tools.

\section{Theme 5: Mentorship, teamwork and School support.}

The school had a structure in place to mentor teachers in their first year of experience. She met with the mentors who assisted her in planning, brainstorming strategies to use in teaching, and how to identify the material. The mentor observed her and provided her feedback on her classroom lessons.

My school understood and supported me in teaching... I was lucky I had a mentor that assisted me in planning... the school provided me with teacher assistants in class, adequate learning space and materials.

Due to the needs of her students, she worked with various professionals in her class, particularly occupational and physical therapists. She also had two teacher assistants in the class.

\section{Theme 6: Collaboration with Parents}

The teachers are involved in setting up the IEP process, such as appointments, paperwork and follow-up with parents. Teachers must communicate and partner with parents in understanding the students 'needs. Some parents are easy to work with while others require school administration to intervene.

\section{Theme 7: Communication}


Ms. Jan's class uses various modes of communication. During observation it was noted that the teacher tended to use Total Communication. Also she used ASL to support reading comprehension. The students used ASL, or typed their responses, or used pictures to communicate Ms. Jan varied her communication mode when interacting with individual students. The teacher uses.

\subsubsection{Ms. Selena}

Ms. Selena is an elementary and middle school teacher with 10 years of experience teaching deaf students, of which 4 of those years have been with deaf students with additional disabilities. She has a bachelor's degree in special education and certification in special education. Before joining deaf education, she had taught students with various special needs. Her deaf students have special education needs including intellectual differences, learning disabilities and Down syndrome.

\section{Theme 1: Becoming a teacher of deaf students with additional disabilities}

Ms. Selena taught deaf students for a few years before she was assigned to teach deaf students with special needs. Currently, she is not teaching a class of deaf students with special needs because her students have been integrated into the regular deaf education program.

"I worked with the students separate but now they are mixed. The school stopped having separate classes for deaf students with special needs. Mixing the deaf students provides experiential learning. . I think it is a great idea because the students are able to interact with other deaf students, which improves their language and social skills... They now demonstrate more use of ASL"

She teaches English language arts and remedial for other subjects content. Based on the students' schedule, Ms. Selena pulls out a deaf student with additional disabilities from regular deaf education classroom.

\section{Theme 2: Influence of teacher preparation}

Ms. Selena shared how her previous training has been instrumental in her current work with deaf students with additional disabilities.

I used my previous experience working with students with severe disabilities for more than 5

years. I was trained to teach students in special education program. My training focused on

students with multiple or severe disabilities.

In particular, her training on classroom management, student's behavior management, innovative strategies to attend to special needs students, and practicum have been beneficial in her current teaching with deaf students. As a special education teacher, she continues to attend webinars on special education which refresh her teacher preparation knowledge and skills and introduce new ideas and strategies. She argued that, although the webinars are on special education and not specifically deaf education, the seminars supported her teaching.

\section{Theme 3: Reflection on a typical day}

The deaf students with additional disabilities learning block sessions include custodial care, language arts, Math, PE, culinary, Social studies, Science and daily living skills. The deaf students with additional disabilities are integrated into the regular deaf education classrooms for Social studies, science and arts.

Ms. Selena teaches individual students language arts and offers remedial support for content covered in inclusive classes.

There are challenges to adjust the material and meet the expectation of the mainstream learning goals. The deaf students with special needs are not learning much. Also their IEP goals do not match the expectations and what is happening in the deaf education classroom.

During classroom observation, Ms. Selena's role appeared to be that of a facilitator. Inclusive classes focus on language and social skills may not be attending to the IEP goals of the students, because they may have only one deaf student with additional disabilities with regular deaf students.. In addition, the regular deaf education teacher may not have the skills, or the time to individually attend to the deaf students with additional disabilities.

\section{Theme 4: Curriculum planning and implementation}

Ms. Selena focuses more on hands-on or experiential learning. The students' activities are authentic and focus on the student's life.

She expressed one challenge in implementing the curriculum is to explain to the administrators, parents and other teachers, the intent of specific activities because her students are in various learning level.

Another challenge is the students rarely communicate their understanding due to significant language delay. 
The students don't communicate during reading and content areas teaching... occasionally they pointed to the pictures.

Ms. Selena uses the accelerated reading program to support students' reading skills. She develops teacher-made tests to for reading assessment. She also uses the Dynamic Learning Maps (DLM), an alternate assessment system and KITE system. DLM is a computer-based assessment for students with significant cognitive disabilities. But even with accommodations, the general state assessments are not appropriate for this population. Most of the activities observed targeted on matching pictures or letters.

\section{Theme 5: Mentorship, teamwork and School support.}

Ms. Selena reported that the teachers are very supportive of one another. When she began teaching was trained in special education. She learned a lot from the other teachers. Ms. Selena was quick to point out the need for teamwork in supporting the deaf students with additional disabilities. She feels the lack of teamwork in planning and preparation may lead to deaf students with additional disabilities' needs ignored.

Ms. Selena expressed the need to have teacher assistants in the inclusive setting to support the students in regular classrooms.

\section{Theme 6: Collaboration with Parents}

Ms. Selena pointed out that she had minimal interaction with parents, apart from IEP meetings. She expressed a need to have more collaboration between the parents and the teacher, in order implement IEP goals at home. She also felt the school administration should seek opportunities to encourage more home-to-school interactions.

\section{Theme 7: Communication}

Ms. Selena's biggest challenge in teaching the deaf students with additional disabilities was communication. She felt there was no clear communication between the teachers and the students. Most of the students with additional disabilities had delayed language, which impeded their communication.

\subsubsection{Tasha}

Tasha is a female middle school teacher who is deaf. She teaches in a deaf education program within a mainstream regular school program. She has more than 5 years teaching deaf students with additional disabilities. She has a master's degree in deaf education but she is not yet certified. Although she is fluent in ASL, she also uses Total communication depending on the students' needs. She reported that the administration provides no assistance or instruction in teaching or managing deaf students with special needs.

\section{Theme 1: Becoming teacher of deaf students with additional disabilities}

Ms. Tasha reflected on her initial experiences and the changes that have occurred since then.

I can remember when I first started teaching; all of the students were in the same classroom. The students who had additional disabilities were with the regular deaf students. I spent a lot more time with those students. They were all in the same classroom, even though those students were not working on the same level as the other students in my class. I think it's much better now that we have the Deaf students with additional disabilities separated from the other deaf students that are in regular classes

She reported that many of the students had no specific documentation of an additional disability and often the evaluation team was not able to identify the student's specific additional disability. Also, her supervisor and principal provided no advice or instruction on how to teach or manage the deaf students with special needs. She felt that her personal experiences as a deaf student had made her a much more compassionate teacher. She has high expectations for the students and as a result they are very motivated to learn.

\section{Theme 2: Influence of teacher preparation}

While pursuing a master's degree in deaf education, Ms. Tasha took one course that focused on deaf with multiple disabilities.

I remember my class from my college gave me lots of ideas but really; I just used trial and error. During my Masters degree, I remember having to take lesson plans and making modifications for different types of deaf students with disabilities.

She expressed the absence of absence of a practicum experience to develop skills on how to teach a class with various special needs, and how to implement the various lesson plan modifications in the classroom. Additionally, she explained that classroom and behavior management was not adequately covered in the course. Ms. Tasha emphasized the need for in-service training for teachers of deaf with additional disabilities.

Since I have been teaching, there has always been a special education program facilitator to assist us with any issues that we may have in the classroom. They also would provide different ideas or strategies, but they did not really know 
things related to deaf students. One year, a facilitator was hired that had many years teaching deaf students. That was really a lot better for all of us. It helped us because she was a teacher of the deaf. I felt that she really knew what we needed to do with our students. That helped me because she would tell us what we were doing wrong and how to fix it.

\section{Theme 3: Reflection on a typical day}

A typical day is set up with one hour and thirty minute block sessions. The students in her class are self-contained except for Physical Education and some elective classes. There was a definite feeling of frustration exhibited as Ms. Tasha summarized her typical day. She is constantly thinking of ways to attend to the students' diverse educational needs. She explained that it is a day comprised with different learning plans for each student. One of the biggest challenges was behavior. She reported that some days the students behaved and followed the rules, while other times, it was a constant battle with them.

I had to come up with different ways to encourage them. I always hated to send them to the principal because I felt they would think I couldn't handle my own students. After a while I got to be much better with handling their behavior.

Her persistence and determination proved to be an important asset to the success of the everyday issues that were prevalent in the classroom.

\section{Theme 4: Curriculum planning and implementation}

It is really frustrating because the school requires that they take the same test at the end of the year. There is no help when they have to take the state tests at the end of the year. The modifications they need are not allowed on these types of tests. I try to make sure that I have papers to show what they have done. It can show how they have improved from the beginning to the end of the year. It is hard for them to do well.

Ms. Tasha's greatest concern was related to the State's expectation on curriculum implementation and assessment. Since the curriculum was developed for regular students, she had to modify it to meet the needs of deaf students with additional disabilities. Ms. Tasha expressed frustration in meeting the regular curriculum objectives based on State exams as opposed to demonstrating growth in learning through authentic assessments. Without adequate training in teacher preparation program, and little or no support from the school district on how to attend to these needs, Ms. Tasha faces a huge challenge in fulfilling her role as a teacher for deaf students with additional disabilities.

\section{Theme 5: Mentorship, teamwork and School support.}

Ms. Tasha depended on how the other teachers utilized accommodations for students with additional disabilities in their classrooms. She felt that these teachers were giving her adequate support and stated that she was able to get "better ideas" from them. She reported that she had a mentor that supported her during her first year. This proved to assist her in understanding the specific needs of individual students. She was also provided with specific in-service training related to students with multiple disabilities.

She also reported her frustration with the administration because they felt that the students in her class should be doing exactly what the regular education students are doing. She felt that the administration did not really understand what these students face on a typical day

It seems each of the students that have other disabilities is very different. None of them are the same. They don't perform the same. Sometimes the supervisor didn't seem to understand the problems these deaf students with additional disabilities have in learning.

\section{Theme 6: Collaboration with Parents}

Ms. Tasha reported that it was often difficult to collaborate with parents. She communicated with parents through notes sent home. She explained that, her interaction was limited to IEP meetings.

Parents will usually attend the meeting for the annual review of the student's IEP. At that time, I discuss their specific needs and areas of strengths and weaknesses. Many times, parents do not have transportation and will receive a mailed copy of the IEP. It makes it difficult because many of the parents live so far away and can't come to the school for different events.

\section{Theme 7: Communication}

Ms. Tasha shared the challenges she experienced with communicating with her deaf students with additional disabilities.

The method of communication used by the school district is Signed English. Since I am Deaf, my method of communication is more of Simultaneous Communication mode. These students have not really learned American Sign Language. I was trained to teach in bilingual methods, but the school policy does not use American Sign Language. I sometimes use ASL signs to help students understand certain ideas and concepts. 


\subsection{Composite Description}

Although educational settings differed (e.g., school for the deaf, deaf education program in a regular education), the data suggest teachers of deaf students with additional disabilities share common teacher's experiences. The data indicated that, classroom experience; prior professional training, colleague and support by school, communication and collaboration with parents are factors that characterized the experience. The four case studies provided teachers an opportunity to voice their classroom experiences and perception of their training and support from their school that impact their current teaching experiences. The four case studies describe the teachers' experiences. The seven related themes primarily experienced by all participants were: their journey in becoming a teacher of deaf students with additional disabilities, a typical day, curriculum planning and implementation, prior training, mentorship, teamwork and administrative support, communication and collaboration with parents.

First, each participant discussed how he or she started a professional journey to teach deaf students with additional disabilities. The participants collectively reported they were assigned to teach these students. The assignment was done without clarification of their roles and expectations and discussion on their professional knowledge and skills to manage the students. Consequently, all participants went through a phase of understanding and learning their students, negotiating support from students' parents and the school and attending to conflicting roles between their training and professional expectations. The teachers valued their students and their patience with them, they reported, was a sustaining and nourishing force in their professional journey.

The study provided the participants with an opportunity to reflect on a typical day as a teacher for deaf students with additional disabilities. This reflection gave them opportunities to think about the teaching and learning process that occurred in their classrooms. With support of the researchers, the participants reflected deeply on their experience teaching deaf students with additional disabilities. In their reflections, the participants described their typical day as a cyclic one that did not begin and end at the end of the workday but rolled over to each moment of their personal life. The success of each day depended on how they maintained a psychological, physical emotional and personal balance. The participants shared various mechanisms they employed to create this balance, such as talking with someone or engaging in relaxation activities such as yoga and meditation.

Overall, no matter the teaching experience of the teacher or the teacher preparation program attended, every teacher reported they were not sufficiently prepared to teach deaf students with additional disabilities. This was evident in their sharing of experiences when they avoided mentioning the effect of their teacher preparation or any ideas introduced into their experiences from their previous teacher preparation programs. Only one teacher reported taking a course on multiple disabilities, but remarked that it was not sufficient in providing skills to manage the classroom. All four teachers expressed the need for training related to curriculum implementation and assessment, alternative communication systems with their students and how to appropriately collaborate with parents.

Also, each of the participants discussed their experience with mentorship, teamwork and school support. Although the experiences differed across participants, the key focus was on the presence or absence of specific topics. The nature of the mentorship, teamwork and school support varied along a continuum from one set by the school, to one initiated by the individual teacher with colleagues. In one organized by the school, the teacher was assigned a mentor who guided them through their initial year and remained as a consultant as needed. On the other hand, the one initiated by the teacher, the teacher sought help by his/herself when needed. The school-organized mentorship, teamwork and support seemed to facilitate a positive transition into teaching deaf students with additional disabilities and the participants expressed less challenges and frustrations.

\section{Implications of the Findings}

The recurring theme in this issue is that of urgency to empower prospective teachers for Deaf and Hard of hearing students to have the skills necessary for this population to be successful. It is critical that teacher-training programs focus on this population of deaf students. Given the high incidence of additional disabilities, every deaf education teacher-preparation should offer one or more courses to meet the needs of these students. Additional training, in the way of additional course requirements at the pre-service and in-service levels, can be included in teacher training curriculums. Specific classes that include the unique needs related to communication, curriculum, assessment and appropriate partnering must be implemented to bring about improved outcomes for these students with additional disabilities. More importantly, prospective teachers should be enrolled in additional practicum experiences with deaf students with additional disabilities. Teacher training programs must reevaluate course offerings related to these students. There is a great need to offer more hands-on experiences with this population of students. Without these changes implemented, this cycle of inadequate success, otherwise known as failure, will continue to run rampant in teacher training programs.

Additionally, the results of this study suggested that teachers need classroom support in handling the students' issues in 
the classroom. From the teachers' voices, the various ways in which the school support can be factored includes understanding and supportive school administration, reviewing teacher's assignments, availability of resources and setting up an internal team support structure. Schools need to set up mentoring guidelines to facilitate smooth teachers' transitions from regular deaf education classrooms to ones that have students with additional disabilities. For school programs with inclusive deaf education programs, that have deaf students, with and without additional disabilities in the same classroom, there is a dire need for professional development in the area of teaching deaf students with additional disabilities.

\section{References}

Bogdan, R., \& Taylor, J. S. (1975). Introduction to qualitative research methods: A phenomenological approach to the social sciences. New York. A Wiley-Interscience publication.

Borders, C. M., \& Bock, S. J. (2012). Preparing teachers of the deaf for acomplex student population. Paper presented at the meeting of the Association of College Educators- Deaf \& Hard of Hearing, Jacksonville, FL.

Bruce, S., DiNatale, P., \& Ford, J. (2008). Meeting the needs of deaf and hard of hearing students with additional disabilities through professional teacher development. American Annals of the Deaf, 15(4), 368-375. http://dx.doi.org/10.1353/aad.0.0058

Creswell, J. W. (1998). Qualitative Inquiry and Research Design. Thousand Oaks, CA. Sage Publications, Inc.

Creswell, J. W. (2008). Research design: Qualitative, quantitative, and mixed methods approaches. London SAGE Publications.

Ewing, K. (2011). Meeting the diverse needs of students with disabilities In D. Moores. (Ed.), Partners in Education issues and trends from the 21st International Congress on the Education of the Deaf (pp.110-131). Washington DC: Gallaudet University Press.

Ewing, K. M., \& Jones, T. W. (2003). An educational rationale for deaf students with multiple disabilities. American Annals of the Deaf, 148, 267-271. http://dx.doi.org/10.1353/aad.2003.0019

Gallaudet Research Institute (2005). Regional and National Summary Report of Data from the 2004-2005 Annual Survey of Deaf and Hard of Hearing Children and Youth. Washington, D.C.: GRI, Gallaudet University.

Gallaudet Research Institute (2006). State Summary Report of Data from the 2006-2007 Annual Survey of Deaf and Hard of Hearing Children and Youth. Washington, DC: GRI, Gallaudet University.

Gallaudet Research Institute (2008). Regional and National Summary Report of Data From the 2007-08 Annual Survey of Deaf and Hard of Hearing Children and Youth. Washington, DC: GRI, Gallaudet University.

Gallaudet Research Institute (2011). Regional and National Summary Report of Data from the 2009-2010 Annual Survey of Deaf or hard of hearing Children and Youth. Washington, DC: GRI, Gallaudet University.

George, N. L., George, M. P., Gersten, R., \& Grosenick, J. R. (1995). To leave or to stay? An exploratory study of teachers of students with emotional and behavioral disorders. Remedial and Special Education, 16(4), 227-236. http://dx.doi.org/10.1177/074193259501600406

Guardino, C. A. (2008). Identification and placement for deaf students with multiple disabilities: Choosing the path less followed. American Annals of the Deaf, 153, 55-64. http://dx.doi.org/10.1353/aad.0.0004

Heyns, B. (1988). Educational defectors: A first look at teacher attrition in the NS-72. Educational Researcher, 17(3), 24-32. http://dx.doi.org/10.3102/0013189X017003024

\section{J. C. V. California School for Deaf California 33 NDLR P 169 F.Supp.2d, WL 2850376 (N.D.Cal.2006).}

Jones, T. W. (1984). A framework for identification, classification, and placement of multi- handicapped hearing impaired students. Volta Review, 86, 142-151.

Jones, T. W., \& Jones, J. K. (2003). Educating Young Children with Multiple Disabilities. In B. Bodner-Johnson \& M. Sass-Lehrer (Eds.), The Young Deaf or Hard of Hearing Child (pp.297-329). Baltimore: Brookes Publishing Co.

Jones, T., Jones, K., \& Ewing, K. (2006). Students with multiple disabilities. In D. Moores \& D. Martin (Eds.) Deaf Learners: Developments in curriculum and instruction (pp 127-144) Washington, DC: Gallaudet University Press New York, NY:Oxford University Press.

Luckner, J. L., \& Carter, K. (2001). Essential competencies for teaching students with hearing loss and additional disabilities. American Annals of the Deaf, 146(1), 7-15. http://dx.doi.org/10.1353/aad.2012.0065

Luckner, J., \& Cooke, C. (2010). A summary of the vocabulary research with students who are Deaf or hard of hearing. 
American Annals of the Deaf, 155(1), 38-67. http://dx.doi.org/10.1353/aad.0.0129

Mertens, D. M. (2010) Research and evaluation in education and psychology: Integrating diversity with quantitative, qualitative, and mixed methods, $3^{\text {rd }}$ ed. Thousand Oaks, CA: Sage.

Miller, M. D., Brownell, M., \& Smith, S. W. (1999). Factors that predict teachers staying in, leaving, or transferring from the special education classroom. Exceptional Children, 65(2), 201-218. http://dx.doi.org $10.1177 / 001440299906500206$

Mitchell, R. E., \& Karchmer, M. A. (2004). Chasing the mythical ten percent: Parental hearing status of deaf and hard of hearing students in the United States. Sign Language Studies, 4(2), 138-163. http://dx.doi.org/10.1353/sls.2004.0005

Moores, D. (2001). Educating the deaf: Psychology, principles, and practices (5th edition). Boston: Houghton Mifflin Company.

Moustakas, C. (1994). Phenomenological Research Methods. Thousand Oaks, CA. Sage Publications, Inc.

Patton, M. (1990). Qualitative evaluation and research methods. Beverly Hills, CA: Sage.

Perigoe, C. B., \& Perigoe, R. (2004). Multiple Challenges, Multiple Solutions: Children with Hearing Loss and Special Needs. The Volta Review, 104(4), 211-214.

Silberman, R. K., Bruce, S. M., \& Nelson, C. (2004). Children with sensory impairments. In Orelove, F. P., Sobsey, D., \& Silberman, R.K. Eds. Educating children with multiple disabilities: A collaborative approach (4th ed., pp. 425-527) Baltimore, MD: Paul H. Brookes.

Singer, J. D. (1993). Are special educators' career paths special? Results from a 13-year longitudinal study. Exceptional Children, 59(3), 262-279.

Sokolowski, R. (2000). Introduction to phenomenology. New York: Cambridge University Press.

Whelan, E. M., \& Kretschmer, R. E. (1996). Hearing-impaired students with multiple disabilities as people who think, communicate, and feel. Volta Review 98(5), (n.p.).

\section{$(\infty c)$ EY}

This work is licensed under a Creative Commons Attribution 3.0 License. 